\title{
The pharmacology and therapeutic potential of (-)-huperzine $A$
}

\author{
This article was published in the following Dove Press journal: \\ Journal of Experimental Pharmacology \\ 5 September 2012 \\ Number of times this article has been viewed
}

\section{Maung Kyaw Moe Tun \\ Seth B Herzon \\ Department of Chemistry, Yale University, New Haven, CT, USA}

Correspondence: Seth B Herzon Department of Chemistry, Yale University, New Haven, Connecticut, 06520, USA

Email seth.herzon@yale.edu
Abstract: (-)-Huperzine A (1) is an alkaloid isolated from a Chinese club moss. Due to its potent neuroprotective activities, it has been investigated as a candidate for the treatment of neurodegenerative diseases, including Alzheimer's disease. In this review, we will discuss the pharmacology and therapeutic potential of (-)-huperzine A (1). Synthetic studies of (-)-huperzine A (1) aimed at enabling its development as a pharmaceutical will be described.

Keywords: Alzheimer's, NMDA, neurodegeneration, natural products, synthesis

\section{Introduction}

The search for bioactive metabolites from the plant kingdom has provided many natural products of therapeutic benefit. In spite of the fact that only $5 \%-15 \%$ of the estimated 250,000 plant species have been screened for natural products, approximately $50 \%$ of all natural product-derived medicines are obtained from botanical sources. ${ }^{1}$ Analgesics such as aspirin and morphine, antimalarials such as quinine and artemisinin, and anticancer agents such as paclitaxel and vincristine are well-known examples of plant-derived medicines.

The club moss Huperzia serrata has been used for centuries in Chinese folk medicine for the treatment of contusion, strain, swelling, and schizophrenia. In 1986, Liu et al reported the isolation of the alkaloid (-)-huperzine A (1) from the extracts of this moss (Figure 1). ${ }^{2}(-)$-Huperzine A (1) was found to possess many of the pharmacological activities, such as acetylcholinesterase (AChE) inhibition, that were originally associated with the dried moss itself. This discovery ignited a large amount of research aimed at evaluating the scope of huperzine's pharmacological effects and its clinical potential. Given that (-)-huperzine A (1) is obtained in low yields $(0.011 \%)$ from the moss, methods to create (-)-huperzine A (1) in the laboratory have also been intensively investigated.

This review will summarize the pharmacological effects of (-)-huperzine A (1) and the studies aimed at evaluating its potential for the treatment of neurological diseases. Efforts to develop practical synthetic routes to (-)-huperzine A (1) are described.

\section{Pharmacological activities and clinical studies Inhibition of acetylcholinesterase}

During neurotransmission, the neurotransmitter acetylcholine (ACh) released from the presynaptic nerve binds to the corresponding receptor. At the postsynaptic 


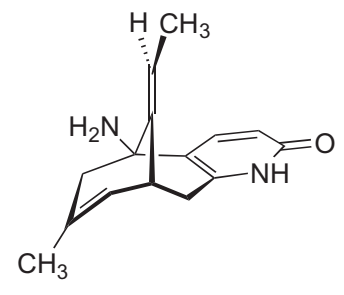

(-)-huperzine A (1)

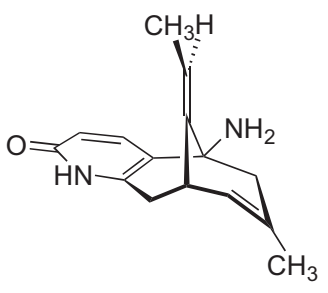

(+)-huperzine A (ent-1, unnatural enantiomer)

Figure I Structures of (-)-huperzine A (I) and (+)-huperzine A (ent-1).

membrane, acetylcholine is hydrolyzed to acetate and choline by acetylcholinesterase to terminate the relay of the neurotransmission.

(-)-Huperzine A (1) is a potent and reversible inhibitor of acetylcholinesterase. The $50 \%$ inhibitory potency $\left(\mathrm{IC}_{50}\right)$ of (-)-huperzine A (1) against acetylcholinesterase in the rat cortex in vitro has been estimated to be $82 \mathrm{nM} .^{3,4}$ This value is greater than that of $( \pm)$-donepezil (2, $10 \mathrm{nM}$; Figure 2), and less than that of tacrine $(3,93 \mathrm{nM})$. This is consistent with the observation that the $\mathrm{K}_{\mathrm{i}}$ value of (-)-huperzine $\mathrm{A}$ (1) stands at $24.9 \mathrm{nM}$, between donepezil (12.5 nM) and tacrine (105 nM). ${ }^{3}$ (-)-Huperzine A (1) shows 900-fold selectivity towards AChE over butyrylcholinesterase (BuChE). By comparison, donepezil and tacrine show lower selectivities (500- and 0.8-fold, respectively). The selectivity towards $\mathrm{AChE}$ over BuChE may help to alleviate undesirable side effects associated with inhibition of BuChE. Although the in vitro AChE activity of (-)-huperzine A (1) lies between that of donepezil (2) and tacrine (3), the oral AChE inhibitory potency of (-)-huperzine A (1) is 24 and 180 times higher than that of either donepezil (2) or tacrine (3), respectively, on a molar basis. ${ }^{4}$

Lineweaver-Burk analysis establishes (-)-huperzine A (1) as a competitive inhibitor of AChE. After sequential incubation with (-)-huperzine A (1) and extraction of the metabolite, $\mathrm{AChE}$ retains its activity, thereby establishing the reversible nature of the $\mathrm{AChE}$-huperzine interaction. ${ }^{5}$ The absolute stereochemistry of (-)-huperzine A (1) is significant for AChE inhibition (but not for all pharmacological effects, vide infra); the unnatural enantiomer (+)-huperzine A (ent-1) is at

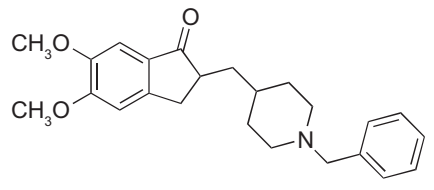

( \pm )-donepezil (2)

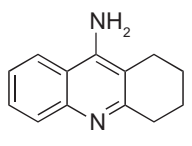

tacrine (3)

Figure 2 Structures of donepezil (2) and tacrine (3).

least 50-fold less potent than the natural isomer (-)-isomer. ${ }^{6}$ This is expected in light of the X-ray crystallographic structure of TcAChE complexed with (-)-huperzine A (1), in which there is a strong interaction between the positively charged amino group of (-)-huperzine A (1) and the aromatic rings of Trp84 and Phe330 in the active site; (+)-huperzine A (ent-1) may not engage in such interactions with the enzyme. ${ }^{7}$ Kozikowski and Tuckmantel have conducted extensive structure-activity studies of (-)-huperzine A (1), and identified a single analog with a higher affinity for $\mathrm{AChE}$ than the natural product. ${ }^{8}$ The high affinity of (-)-huperzine A (1) towards acetylcholinesterase has facilitated the generation of a number of proposals for its use in the treatment of Alzheimer's disease (AD) and as a pretreatment against organophosphate nerve agents.

Although the exact etiology of $\mathrm{AD}$ remains unknown, the symptoms of $\mathrm{AD}$ are associated with cholinergic deficiencies; ${ }^{9}$ thus, (-)-huperzine A (1) has been investigated as a treatment for Alzheimer's disease (AD) (vide infra). Since 1996, (-)-huperzine A (1) has been approved for the treatment of mild-to-moderate AD in China. ${ }^{10}(-)$-Huperzine A (1) is widely available in the US nutraceutical market.

Organophosphate nerve agents such as soman and sarin are classified by the United Nations as weapons of mass destruction. ${ }^{11}$ They exert their toxicity via irreversible phosphorylation of AChE. The effects of this modification range from minor symptoms, such as respiratory distress and hypersalivation, to severe symptoms including seizures and incapacitation. At high doses of these agents, death ensues.

The current method to protect against these warfare agents involves pretreating subjects with reversible AChE inhibitors such as pyridostigmine (4; Figure 3). ${ }^{12}$ Pyridostigmine (4) reacts with AChE to form a cabamoylated enzyme of transient stability. Over the course of a few hours, this modification is reversed to liberate AChE. This reversible blocking strategy provides a mechanism to shield $\mathrm{AChE}$ while the nerve agent is metabolized. However, as it cannot pass the blood-brain barrier, pyridostigmine (4)

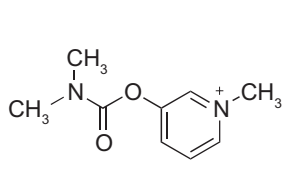

pyridostigmine (4)

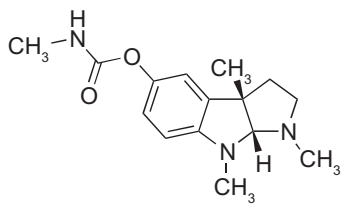

(-)-physostigmine (5)
Figure 3 Structures of pyridostigmine (4) and physostigmine (5). 
only protects peripheral AChE. It should be noted that a related molecule, (-)-physostigmine (5), can cross the blood-brain barrier; however (-)-physostigmine (5) induces undesirable side-effects such as nausea, vomiting, diarrhea, and anorexia. ${ }^{13,14}$

There have been numerous studies assessing the prophylactic potential of (-)-huperzine A (1) against organophosphates. ${ }^{15-18}$ One study involved the measurement of $\mathrm{LD}_{50}$ of soman given to mice (subcutaneous injection, $\mathrm{SC}$ ) pre-administered with (-)-huperzine A (1) $(500 \mu \mathrm{g} / \mathrm{kg}$, intraperitoneal injection, IP) and (-)-physostigmine (5) $\left(100 \mu \mathrm{g} / \mathrm{kg}\right.$, intramuscular injection). ${ }^{15}$ (-)-Huperzine A (1) conferred a 2 -fold protective ratio for 6 hours. By comparison, pretreatment with (-)-physostigmine (5) provided a protective ratio of 1.5 for only 1.5 hours. In a separate study, soman-induced seizures and subsequent neuropathological changes of guinea pigs pretreated with (-)-huperzine A (1) $(500 \mu \mathrm{g} / \mathrm{kg}$, IP) and pyridostigmine (4) $(200 \mu \mathrm{g} / \mathrm{kg}$, subcutaneous injection, SC) were compared. ${ }^{16}$ All guinea pigs pretreated with (-)-huperzine A (1) survived and did not exhibit neuropathological abnormalities. Those pretreated with pyridostigmine (4) suffered extensive neurological damage; five out of six animals died.

As expected, there is a correlation between $\mathrm{AChE}$ inhibition and the cellular levels of ACh. ${ }^{17}$ A dose of $100 \mu \mathrm{g} / \mathrm{kg}$ of (-)-huperzine A (1) administered to mice inhibits AChE of $2.5 \% \pm 0.9 \%$ (means \pm SEM, $n=21$ ); this results in an approximate 5.5-fold increase in levels of ACh. A high dose of (-)-huperzine A (1) $(500 \mu \mathrm{g} / \mathrm{kg})$ produces a $21.5 \% \pm 1.6 \%$ inhibition of AChE, resulting in $12.9 \pm 3.4$ (means \pm SEM, $\mathrm{n}=19$ ) times the basal ACh level. Although this high level of inhibition completely prevents lethality and seizures from soman-induced toxicity in mice (up to $124 \mu \mathrm{g} / \mathrm{kg}$, SC), ${ }^{16}$ it also induces minor hypercholinergic symptoms such as chewing, salivation, fasciculation, and tremors. ${ }^{17}$ To attenuate these cholinergic symptoms, a recent study reported the efficacy of combining (-)-huperzine A (1) $(50 \mu \mathrm{g} / \mathrm{kg}$, SC) and imidazenil (6) $(2000 \mu \mathrm{g} / \mathrm{kg})$ (Figure 4). This binary mixture provided a powerful prophylactic strategy against diisopropylfluorophosphate-induced toxicity in mice without observable hypercholinergic symptoms and neuronal damage, resulting in $0 \%$ mortality compared with $100 \%$ mortality for those treated with either the vehicle and diisopropylfluorophosphate or diisopropylfluorophosphate alone. ${ }^{19}$

\section{Attenuation of $\beta$-amyloid toxicity}

Extracellular senile plaques are a histological hallmark in the brains of AD patients. ${ }^{20}$ The major components of the

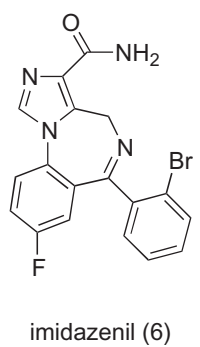

Figure 4 Structure of imidazenil (6).

senile plaques are $\beta$-amyloid $(A \beta)$ fragments, which are short peptides containing 36-43 amino acids. $\beta$-amyloid $(A \beta)$ fragments are formed by proteolysis of the membranebound amyloid precursor protein (APP). ${ }^{21}$ APP is cleaved by at least two pathways, one of which is the $\alpha$-secretase non-amyloidogenic pathway in which peptidase proteins of disintegrin and metalloprotease families cleave APP into soluble $\alpha$-APP fragments, and then release them into the extracellular media. ${ }^{22} \alpha$-APP fragments have been shown to be both neurotrophic ${ }^{23}$ and neuroprotective. ${ }^{24}$ However, APP can be processed by a second pathway known as $\beta / \gamma$-secretase amyloidogenic pathway, which results in the generation of the insoluble $A \beta$ fragments. $A \beta$ has been reported to trigger apoptotic responses, such as neuronal membrane blebbing and cell shrinkage, leading to cell death. ${ }^{25}$ Consequently, several potential therapeutic strategies for $\mathrm{AD}$ seek to modify the $\beta / \gamma$-secretase amyloidogenic processing pathway.

There have been several studies suggesting an association between $\mathrm{AChE}$ activity and $\mathrm{A} \beta$ formation. There is evidence that $\mathrm{AChE}$ co-localizes with $\mathrm{A} \beta$ deposits in AD patients. ${ }^{26}$ Evidence also suggests that $\mathrm{AChE}$ forms a stable complex with $\mathrm{A} \beta$ and promotes the aggregation of $\mathrm{A} \beta$ deposits. ${ }^{27}$ This association changes the enzymatic activity of AChE and increases the neurotoxicity of the $\mathrm{A} \beta$ deposits. ${ }^{28}$

The apparent relationship between AChE activity and $A \beta$ deposition suggests (-)-huperzine A (1) may influence $A \beta$-induced neurotoxicity. For instance, it was found that (-)-huperzine A (1) attenuated $A \beta$-induced memory deficiency and neurodegeneration in rats. ${ }^{29}$ In a Morris water maze test, rats were administered either a mixture of $\mathrm{A} \beta_{1-40}$ (intracerebroventricular infusion) and (-)-huperzine A (1) $(0.1$ or $0.2 \mathrm{mg} / \mathrm{kg}$, IP, once per day for 12 consecutive days), $A \beta_{1-40}$ (intracerebroventricular infusion) alone, or a vehicle control. Rats in the group receiving $\mathrm{A} \beta_{1-40}$ alone took longer to find the platform than those that received $\mathrm{A} \beta_{1-40}$ co-administered with (-)-huperzine $\mathrm{A}(1)$ and those that received the vehicle. In a probe trial test, rats treated with 
(-)-huperzine $A(1)$ and $A \beta_{1-40}$ spent more time in the probe quadrant than those treated with $A \beta_{1-40}$ alone. (-)-Huperzine A (1) significantly reduced pathologic deformations induced by $\mathrm{A} \beta_{1-40}$ in both the cortex and the hippocampus of rats, and attenuated the formation of amyloid deposits throughout the cortex. $^{29}$

In addition to reducing the toxicity induced by $A \beta$, (-)-huperzine A (1) has been reported to direct the processing of APP toward the $\alpha$-secretase non-amyloidogenic pathway. ${ }^{30}$ A dose-dependent increase in the release of $\alpha$-APPs, and the inhibition of A $\beta$ in human embryonic kidney 293 cells transfected with human APP bearing the Swedish mutation (HEK293 APPsw) was noted after the administration of (-)-huperzine A (1). The increase in the secretion of $\alpha$-APPs might be regulated via protein kinase $\mathrm{C}$ and mitogenactivated protein kinase pathways, as the corresponding kinase inhibitors significantly reduced the (-)-huperzine A (1)-induced release of $\alpha$-APPs. ${ }^{30,31}$

Since (-)-huperzine A (1) inhibits AChE 50-fold more efficiently than the (+)-enantiomer ent-1, the relationship between absolute stereochemistry and attenuation of $\mathrm{A} \beta$ toxicity has been studied. ${ }^{32}$ Surprisingly, it was found that both enantiomers of huperzine A have similar potencies towards the amelioration of $\beta$-amyloid toxicity in NG108-15 and $\mathrm{PC}$ cells exposed to $\mathrm{A} \beta_{25-35}$. This would suggest that the neuroprotective properties of either enantiomer of huperzine do not have a direct relationship to their AChE inhibitory activities.

\section{Protection against glutamate-induced neurotoxicity}

Glutamate receptors are important for the modulation of synaptic plasticity and play significant roles in memory and learning. ${ }^{33}$ Two primary glutamate receptors, named for the agonists that bind to them, are the AMPA ( $\alpha$-amino-3hydroxyl-5-methyl-4-isoxazole-propionate) and NMDA (N-methyl-D-aspartate) receptors. Recently, NMDA receptors have gained much attention given that their overexcitation is involved in many neurodegenerative diseases, such as epilepsy ${ }^{34}$ and AD. ${ }^{35}$ A large body of evidence suggests that suppressing NMDA receptors with antagonists is effective in the attenuation of these diseases. ${ }^{36}$

Excessive glutamate overstimulates the NMDA receptors, leading to an influx of calcium ions. This influx of calcium is accompanied by a cascade of cell degradation processes, ultimately leading to neuronal cell death. ${ }^{37}$ Consequently, this excitotoxicity is believed to be a significant contributor to the progression of several neurodegenerative diseases. ${ }^{38}$
It has been shown that (-)-huperzine A (1) prevents glutamate-induced calcium mobilization in cell cultures. ${ }^{39}$ Treatment of cerebellum cell cultures from rat embryos with $100 \mu \mathrm{M}$ glutamate resulted in the death of $55 \%$ of the neurons when compared to vehicle control cultures. Pretreatment of the cells with $100 \mathrm{nM}(-)$-huperzine A (1) before the addition of glutamate decreased the mortality rate to $30 \%$. A correlation between calcium ion concentration and the concentration of (-)-huperzine A (1) was also observed. Thus, treatment with $10 \mu \mathrm{M}$ glutamate increased calcium ion concentration by $811 \pm 3 \mathrm{nM}$ (means $\pm \mathrm{SEM}, \mathrm{n}=99$ ). However, this change was reduced by $20 \%$, to $668 \pm 4$ (means \pm SEM, $n=102$ ) after treatment with $100 \mathrm{nM}(-)$-huperzine A (1). Treatment of cell cultures with $100 \mu \mathrm{M}$ glutamate also induced significant morphological changes, including the diffusion of cell aggregates and the reduction of axon-like processes. However, pretreatment of the cultures with $100 \mathrm{nM}(-)$-huperzine A (1) attenuated these phenotypes.

In a related study, the attenuation of cell death in neuronal cultures exposed to NMDA and (-)-huperzine A (1) was determined. ${ }^{40}(-)$-Huperzine A (1) inhibited NMDAinduced toxicity $(500 \mu \mathrm{M})$ in a dose-dependent fashion. Thus, cells treated with approximately $10 \mu \mathrm{M}(-)$-huperzine A (1) had a survival rate of $85 \%$, as opposed to $35 \%$ in the control group. The NMDA receptor antagonistic character of (-)-huperzine A (1) has been attributed to its binding proximal to the MK-801 (dizocilpine) and phencyclidine binding sites. ${ }^{40}$

The extent of NMDA-receptor antagonism as a function of huperzine stereochemistry has been the subject of several studies; the NMDA-receptor antagonism exhibited by huperzine A does not appear to be stereodependent. Thus, (-)-huperzine A (1) and (+)-huperzine A (ent-1) inhibited the binding of MK-801 in the cerebral cortex of rats with similar potencies $\left(\mathrm{IC}_{50}\right.$ values of $65 \pm 7 \mu \mathrm{M}$ and $82 \pm 12 \mu \mathrm{M}$ for $(-)$ - and $(+)-1$, respectively [means \pm SEM, $\mathrm{n}=5$ for each isomer]). ${ }^{41}$ In another study, $(+)$-huperzine A (ent-1) was found to be an effective pre- and postexposure treatment against NMDA-induced seizures. ${ }^{42}$ This suggests that the NMDA-receptor antagonist activity of huperzine A is independent of its AChE inhibitory activity. These studies suggest that the NMDA receptor antagonist activity of huperzine A (1) warrants further investigation.

\section{Protection against free radicals}

A large body of data suggests that free radical-mediated oxidative injury caused by reactive oxygen species serves as a contributing factor to many neurodegenerative diseases, 
including $\mathrm{AD} .^{43,44}$ Many structures in the brain, especially phospholipids, are susceptible to oxidative injury. Several studies have concluded that the brains of AD patients, when compared with age-matched controls, show higher levels of reactive oxygen species-generating elements, such as iron, ${ }^{45-47}$ higher concentrations of protein oxidation biomarkers, ${ }^{48,49}$ a greater extent of oxidative neuronal DNA damage,,$^{50,51}$ and increased production of malondialdehyde from lipid peroxidation. ${ }^{52,53}$

Several studies have established the protective potential of (-)-huperzine A (1) against free radical oxidative injury. Levels of malondialdehyde in the hippocampus decreased from $5.3 \pm 0.23 \mu \mathrm{mol} / \mathrm{L}$ (means $\pm \mathrm{SEM}$ ) in aged rats treated with saline to $2.5 \pm 0.12 \mu \mathrm{mol} / \mathrm{L}$ (means $\pm \mathrm{SEM}$ ) in aged rats treated with (-)-huperzine A (1) (50 ng/kg, bid, 7 days). This was accompanied by a corresponding decrease in the concentration of the protein manganese superoxide dismutase (from $6.0 \pm 0.40 \mathrm{kU} / \mathrm{g}$ protein to $4.5 \pm 0.35 \mu \mathrm{mol} / \mathrm{L}$, means \pm SEM), suggesting a decrease in radical scavenging activity. ${ }^{54}$

It has been reported that the toxicity of $\mathrm{A} \beta$ is mediated by hydrogen peroxide. ${ }^{55}$ The neurotoxicity of hydrogen peroxide is well-recognized, ${ }^{56}$ since it produces highly reactive hydroxyl radicals ( $\left.\mathrm{HO}^{\circ}\right)$. Hydrogen peroxide can be easily formed in the body by the dismutation of superoxide radical $\left(\mathrm{O}_{2}^{-}\right)$, which itself is generated from the reduction of molecular oxygen $\left(\mathrm{O}_{2}\right)$ by $\mathrm{Fe}^{2+}$. (-)-Huperzine A (1) was shown to ameliorate hydrogen peroxide-induced oxidative injury by enhancing the activities of endogenous antioxidant enzymes such as glutathione peroxidase, catalase, and superoxide dismutase. ${ }^{57}$

\section{Clinical trials}

Many studies, including those outlined above, have established the efficacy of (-)-huperzine A (1) in tissue culture and animal models. ${ }^{29,58-60}$ Consequently, the investigation of (-)-huperzine A (1) in human subjects is an area of intensive research. A number of human clinical trials have been conducted in China and the United States.

A double-blind, parallel, placebo-controlled, multi-centered trial conducted in China, involving 103 age-matched patients who met specific AD criteria, confirmed the efficacy of (-)-huperzine A (1) on memory, cognition, and behavior. ${ }^{61}$ Results on the Wechsler Memory Scale, Hasegawa Dementia Scale, the Mini-Mental State Examination (MMSE), and activities of daily living were measured. A total of $58 \%$ (29/50) of the patients treated with four tablets of (-)-huperzine A (1) (200 $\mu \mathrm{g}$ po, bid, 8 weeks) showed significant improvements in memory $(P<0.01)$, cognition $(P<0.01)$, and behavior $(P<0.01)$, compared with $36 \%$ $(10 / 53)$ of the patients treated with placebo tablets $(70 \mathrm{mg}$ po, bid, 8 weeks). A mean improvement of 2.98 points on the MMSE was observed among the (-)-huperzine A (1)-treated patients, compared to 0.43 points among the placebo group. No serious side effects were observed in patients treated with (-)-huperzine A (1). When compared with the potentially hepatotoxic tacrine (3), which produced a mean improvement of 2.0 points in MMSE, (-)-huperzine A (1) is a better candidate for the symptomatic treatment of AD.

In another multicentered, prospective, double-blind, double-mimic, parallel, positive-controlled, randomized study in China, the difference in efficacy of (-)-huperzine A (1) capsules and tablets ( 4 pills, $50 \mu \mathrm{g} /$ pill po, bid, 60 days) was studied across 60 patients who met the criteria for a probable diagnosis of AD. ${ }^{62}$ Patients treated with (-)-huperzine A (1) capsules and tablets showed no difference in their degree of improvement. Moreover, in both groups, pathological changes in the plasma and erythrocytes were ameliorated. The efficacy of (-)-huperzine A (1) was further demonstrated in another prospective, placebo-controlled, double-blind, randomized clinical trial conducted in China with 202 patients diagnosed with $\mathrm{AD} .{ }^{63}$ The results unambiguously established that those treated with (-)-huperzine A (1) ( $\mathrm{n}=100,400 \mu \mathrm{g} /$ day, 12 weeks) showed significant improvements in cognition, behavior, and activities of daily living when compared with those treated with placebo $(n=102)$.

The memory and learning enhancement effects of (-)-huperzine A (1) were also investigated in 34 pairs of matched junior middle school students in a doubleblind clinical trial in China. ${ }^{64}(-)$-Huperzine A (1) (2 capsules, $50 \mu \mathrm{g} /$ capsule, bid) was administered orally for 4 weeks. The memory quotient from the Wechsler Memory Scale results showed an increase from $92 \pm 7$ to $115 \pm 7$ (means \pm SEM, $n=34$ ), as compared to the placebo group, that demonstrated an increase from $94 \pm 8$ to $104 \pm 9$. The performance of students in the (-)-huperzine A (1)-treated group as determined by Chinese-language lesson quizzes was also higher (odds $=10 \pm 9$, in contrast with $2 \pm 7$ in the placebo group).

A Phase II trial of (-)-huperzine A (1) for treating mild-tomoderate $\mathrm{AD}$ has been completed in the US ${ }^{65}$ This study was a multicentered, prospective, three-arm, randomized, doubleblind, dose-escalation trial employing 210 patients. A group of patients administered (-)-huperzine A (1) at $200 \mu \mathrm{g}$ bid did not show any significant improvements in the ADAS-Cog (Alzheimer's Disease Assessment Scale-Cognitive Subscale). 
However, a group administered $400 \mu \mathrm{g}$ of (-)-huperzine A (1) bid showed a 2.27-point increase in the ADAS-Cog scale, whereas the placebo group showed a 0.29-point decline at 11 weeks. At week 16, the ADAS-Cog scale showed 1.92-point increase in the $400 \mu \mathrm{g}$ bid group and a 0.34-point increase in the placebo arm. (-)-Huperzine A (1) was demonstrated to be well-tolerated at doses up to $400 \mu \mathrm{g}$ bid for 24 weeks, and even in subjects who exhibited undesirable symptoms on treatment with other $\mathrm{AChE}$ inhibitors.

\section{Synthetic studies}

The manifold pharmacological effects of (-)-huperzine A (1) have attracted much attention from the academic, pharmaceutical, and defense sectors. However, the clinical development of (-)-huperzine A (1) has been impeded by its limited supply from natural sources. Extraction from natural sources is low-yielding (the average yield is $0.011 \%$ from the dried herb), ${ }^{66}$ and unregulated overharvesting has decimated the populations of Huperziaceae. ${ }^{10}$ Moreover, the species that produce (-)-huperzine A (1) require nearly 20 years from spore germination to maturity, and are not amenable to large-scale cultivation. ${ }^{10}$

As such, laboratory total synthesis offers a very attractive potential source of (-)-huperzine A (1), and to date, there have been a number of total, formal, partial racemic, or enantioselective syntheses of huperzine A. One of the first total syntheses of $( \pm)$-huperzine A was reported by Xia and Kozikowski in 1989 (Figure 5). ${ }^{67}$ The compound 1,4-cyclohexanedione monoethylene ketal (7) was transformed to the key $\beta$-ketoester 8 in six steps and $35 \%$ overall yield. The $\beta$-ketoester 8 was then subjected to a tandem Michael addition-aldol condensation with methacrolein (9), using 1,1,3,3-tetramethylguanidine (TMG) as a promoter. The bicyclic product formed 10 was successfully transformed to $( \pm)$-huperzine A in eight additional steps.
Contemporaneous with Xia and Kozikowski's work, Qian and $\mathrm{Ji}^{68}$ reported a total synthesis of $( \pm)$-huperzine A (Figure 5). Their strategy was similar to that of Xia and Kozikowski ${ }^{67}$ and employed the same $\beta$-ketoester intermediate 8. Using sodium methoxide as the base (rather than TMG, as in Xia and Kozikowski's work), the $\beta$-ketoester 8 was coupled with methacrolein (9) in 96\% yield. The conversion of 10 to $( \pm)$-huperzine A was then achieved in seven steps.

Subsequently, Kozikowski et al reported a more efficient route to the key $\beta$-ketoester intermediate 8 (Figure 6A). This modified route proceeded in four steps and $48 \%$ overall yield from 1,4-cyclohexanedione monoethylene ketal (7) and methyl propiolate (12), via the pyridone $13 .{ }^{69}$ Chassaing et $\mathrm{al}^{70}$ and Haudrechy et $\mathrm{al}^{71}$ later developed an alternative strategy to access the $\beta$-ketoester 8 in six steps and 24\% yield from 2-hydroxy-6-methylpyridine 14 (Figure 6B).

In 1991, Yamada et al reported an enantioselective route to (-)-huperzine A (1), which employed the chiral auxiliary (-)-8-phenylmenthol to induce diastereoselectivity in the key tandem Michael addition/aldol condensation step. Under these conditions, the product 17 was obtained in $90 \%$ yield and 4:1 dr (Figure 7A). ${ }^{72}$ Unfortunately, the chiral auxiliary significantly compromised both the yield and the number of operations required to reach the target; the isomerization of 19 to 20 was inefficient, and provided a modest $\mathrm{E} / \mathrm{Z}$ ratio of 1.4:1 after two repetitions. In addition, the chiral auxiliary (-)-8-phenylmenthol ester could not be directly hydrolyzed; reduction to the primary alcohol (lithium aluminum hydride) and reoxidation (Jones' reagent) were required to remove the auxiliary.

Kaneko et al investigated the tandem Michael addition/ aldol condensation of the $\beta$-ketoester 8 using a chiral amine base as a promoter (Figure $7 \mathrm{~B}) .^{73,74}$ Among several chiral amines screened, (-)-cinchonidine (21) provided the annulated product 23 in $9.5 \%-29 \%$ yield and $64 \%$ ee over three steps.

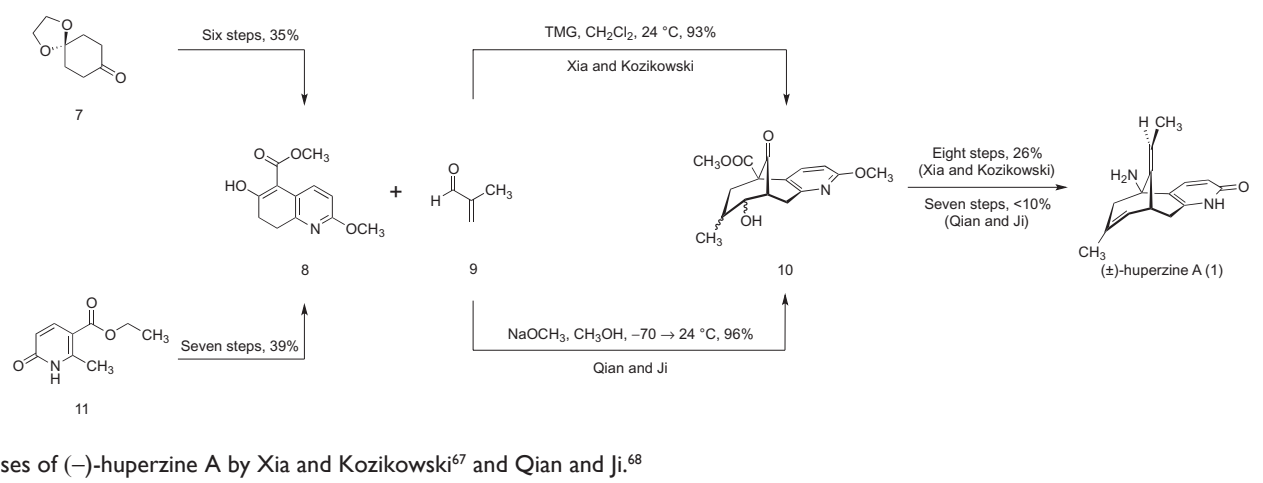

Figure 5 Total syntheses of (-)-huperzine A by Xia and Kozikowski ${ }^{67}$ and Qian and ji. ${ }^{68}$ 
A

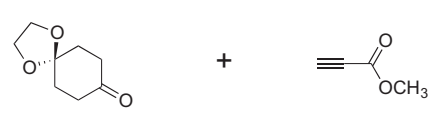

7

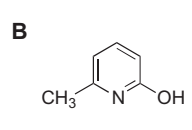

14

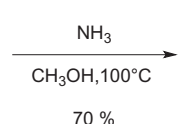

$70 \%$

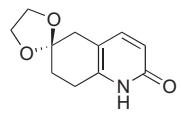

13

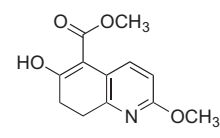

8

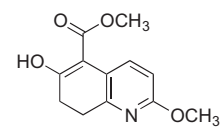

Figure 6 Improved syntheses of the key $\beta$-ketoester intermediate 8 . Kozikowski et al's improved synthesis of the key $\beta$-ketoester intermediate 8 (A); ${ }^{68}$ Chassaing et al's ${ }^{69}$ and Haudrechy et al's ${ }^{70}$ route to 8 (B).

A significant improvement came from the introduction of a palladium-catalyzed bicycloannulation by Campiani et al in 1993. This transformation provided the intermediate 25 , which was readily converted to $( \pm$ )-huperzine A (Figure 8A). ${ }^{75}$ Using 2-methylene-1,3-dipropanediol acetate (24) as electrophile, the bicycloannulation proceeded smoothly in the presence of $5 \mathrm{~mol} \%$ palladium acetate, TMG, and triphenylphosphine to provide the tricyclic product 25 in $92 \%$ yield. The tricyclic product 25 could be transformed to ( \pm )-huperzine A in five steps.

This efficient bicycloannulation not only improved the overall yield but also rendered the synthesis amenable to ligand-induced enantioselective modification, and this possibility was explored by several research groups (Figure 8B). By employing the chiral ferrocene ligand 26 (40 mol\%), Kaneko et al obtained the tricyclic product 25 in $92 \%$ yield and $64 \%$ ee. ${ }^{76}$ The ee could be improved to $>99 \%$ by recrystallization of the endocyclic olefin 27; however, the low yield after recrystallization (37\%) coupled with the high loading of 26 diminished the efficiency of this approach. In 2001, He et al reported that the annulation of product 25 could be obtained in $82 \%$ yield and $90.3 \%$ ee using the ferrocene ligand $28(11 \mathrm{~mol} \%){ }^{77}$

In 2002, Lee et al described a formal synthesis of $( \pm$ )-huperzine A. A key step in their synthesis involved the manganese-mediated oxidative cyclization of the $\beta$-ketoester 8 (Figure 9A) ${ }^{78}$ The $\alpha$-quaternary ketone 30 was obtained by alkylation of the $\beta$-ketoester 8 with 3-bromo-2methylprop-1-ene (29). Treatment of 30 with excess manganese acetate and one equivalent of copper acetate formed a mixture of the exocylic olefin 25 (40\%) and the endocyclic olefin 27 (21\%).

Ward and Caprio prepared the selenide 32 in five steps and $17 \%$ yield from 5-bromo-6-methyl-2-methoxypyridine (31; Figure 9B). ${ }^{79}$ A pyridyl radical was formed by treatment with tributyltin hydride $\left(n-\mathrm{Bu}_{3} \mathrm{SnH}\right)$ and azobisisobutyronitrile;

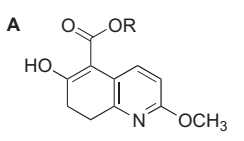

16
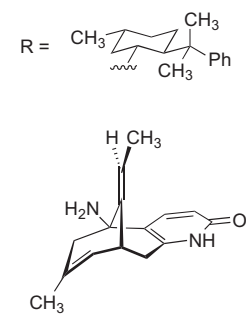

(-)-huperzine A (1)

B

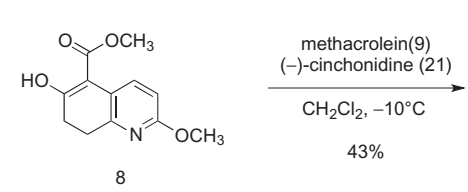

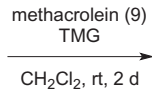

$90 \%$

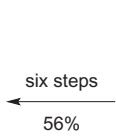

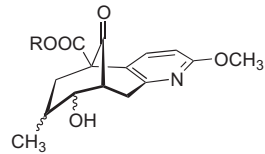

17

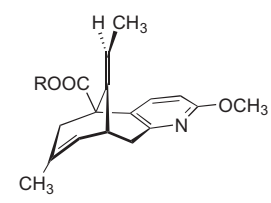

$20(E / Z=1.4: 1)$

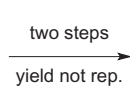

yield not rep.
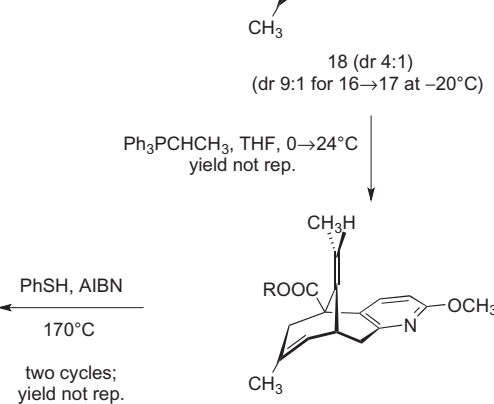
two cycles;
yield not rep.

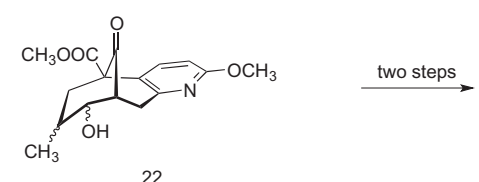

22

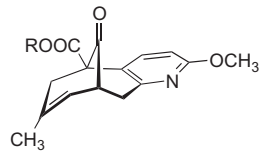

$18(\mathrm{dr} 4: 1)$

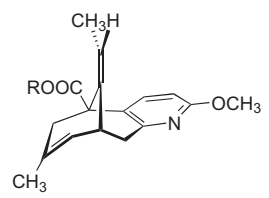

$19(E / Z=1: 10)$

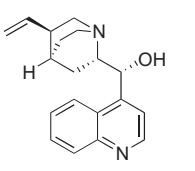

(-)-cinchonidine (21)

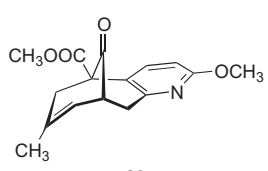

23

$22-67 \%$
$64 \%$ ee

Figure 7 Yamada et al's route to (-)-huperzine A $(\mathbf{A})^{72}$ and enantioselective Michael addition/aldol condensation by Kaneko et al (B)..$^{73,74}$ 

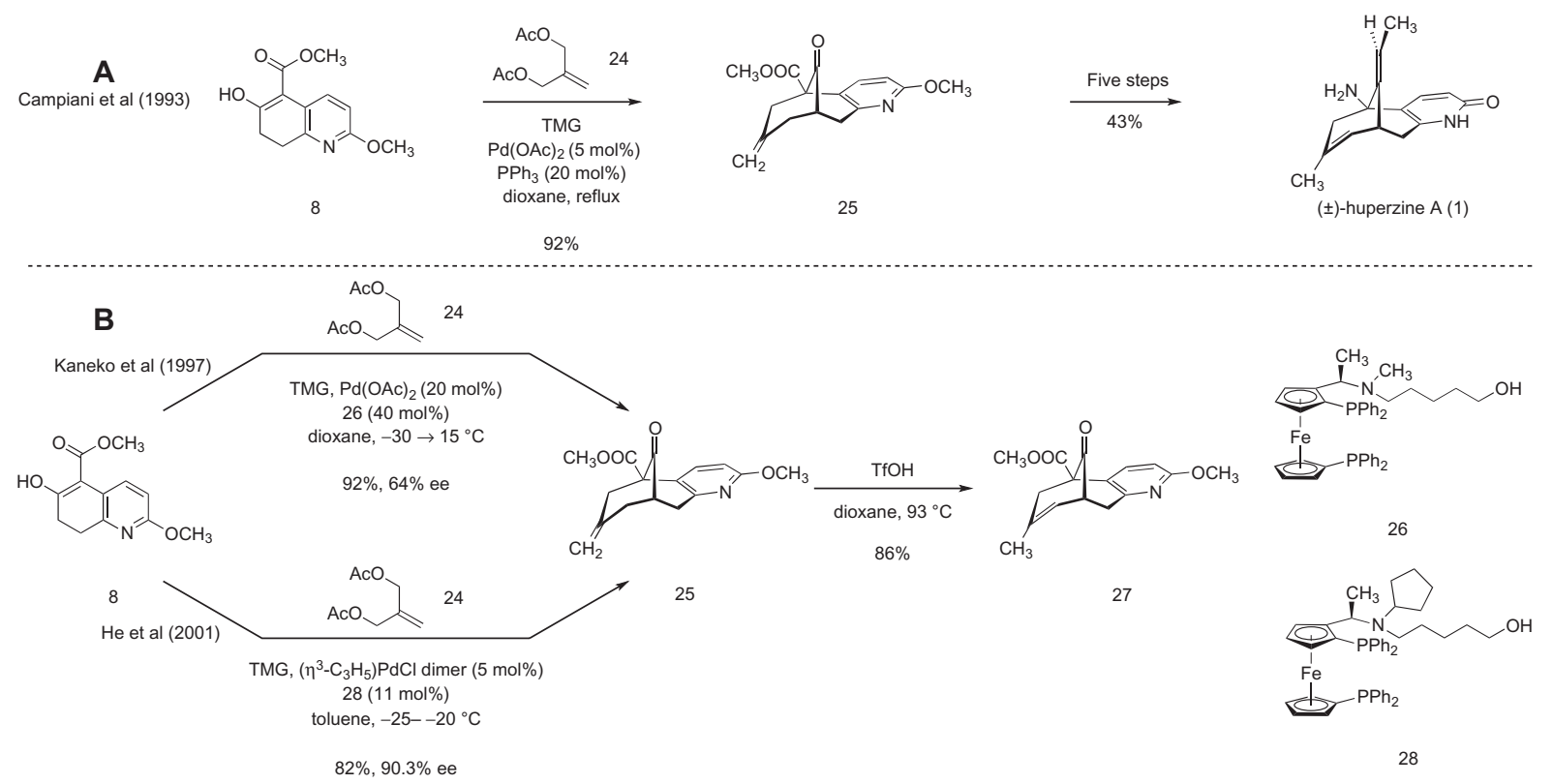

Figure 8 Campiani et al's palladium-catalyzed annulation strategy $(\mathbf{A}) ;{ }^{74}$ Kaneko et al's and He et al's asymmetric palladium-catalyzed annulation strategies $(\mathbf{B}) .{ }^{75,76}$

A<smiles>COC(=O)C1=C(O)CCc2nc(OC)ccc21</smiles>

8
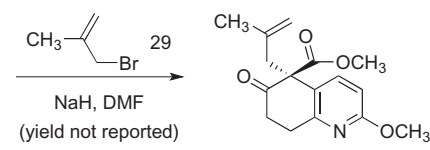

$( \pm)-30$

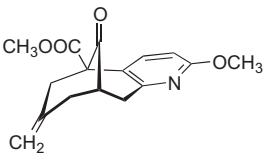

$( \pm)-25(40 \%)$

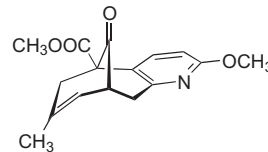

$( \pm)-27(21 \%)$

B

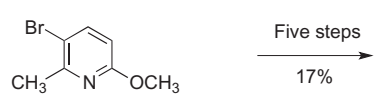

31

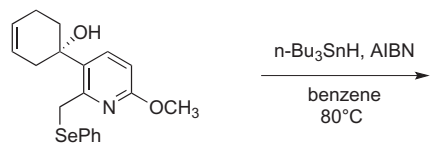

$( \pm)-32$

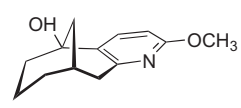

$( \pm)-33(46 \%)$

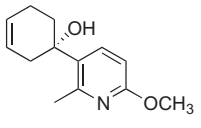

$( \pm)-34(54 \%)$

Figure 9 Lee et al's manganese-mediated oxidative cyclization $(\mathbf{A}) ;{ }^{78}$ approach to $( \pm)$-huperzine A by Ward and Caprio ${ }^{79,80}$ and Ward et al ${ }^{81}(\mathbf{B})$.

A
A

35

(two steps from cyclohex-2-ene-1-one)
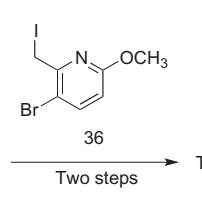

$57 \%$

\section{B}

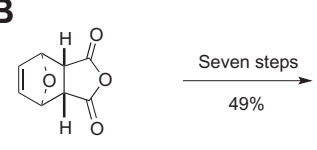

(士)-39

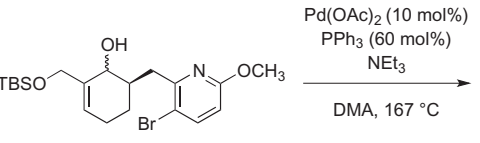

$72 \%$
Seven steps

( \pm -38

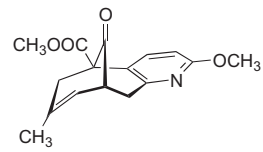

( \pm )-27
$2.9 \%$ from 35 diastereomers

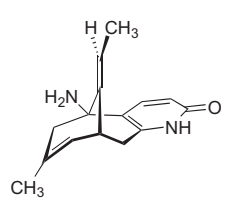

(-)-huperzine A (1)

$1.8 \%$ from ( \pm )-39

Figure 10 Formal synthesis of huperzine $A$ by Lucey et al $(\mathbf{A}) ;{ }^{82}$ total synthesis of $(-)$-huperzine $A(I)$ by Koshiba et al $(\mathbf{B}){ }^{83}$ 


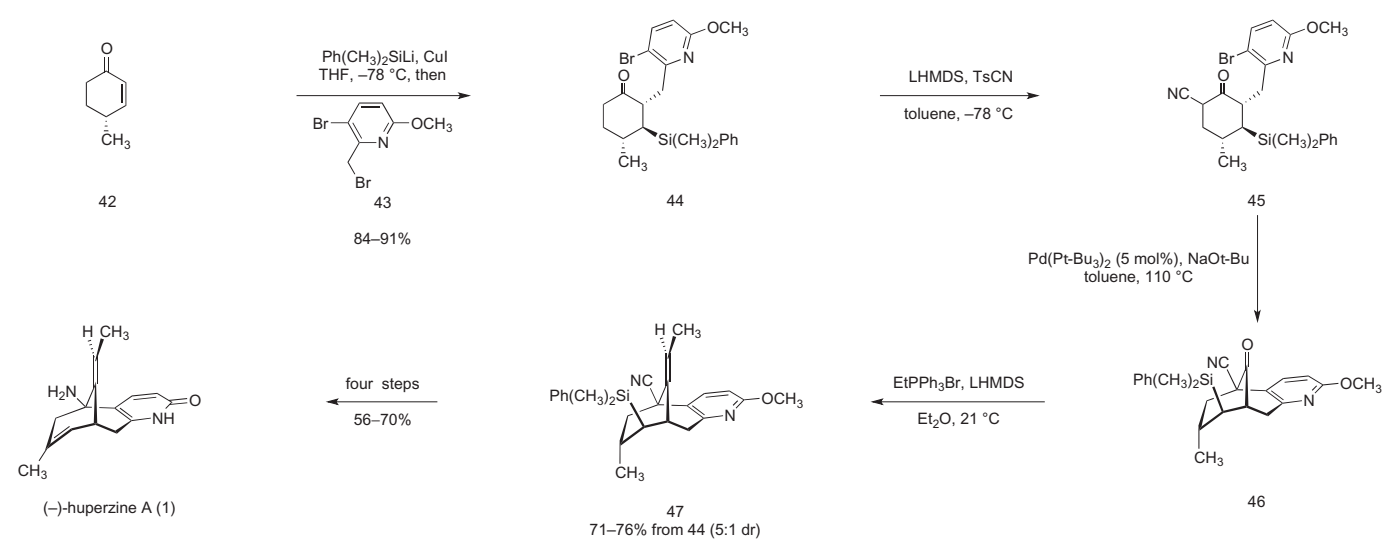

Figure I I Synthesis of (-)-huperzine A (I) by Tun et al. ${ }^{84}$

subsequent 6-exo-trig cyclization produced the alcohol 33 (46\%) along with the reduction product 34 (54\%). Ward and Caprio ${ }^{80}$ and Ward et $\mathrm{a}^{81}$ further demonstrated this methodology with several structurally-related precursors. However, the synthesis of ( \pm )-huperzine A has yet to be completed by this route.

In 2007, Lucey et al reported a formal synthesis of ( \pm )-huperzine A (Figure 10A). ${ }^{82}$ The protected cyclohexenone 35 was coupled with the dihalopyridine 36 to form the alcohol 37 as a $92: 8$ mixture of syn and anti diastereomers after reduction of the carbonyl group. Intramolecular Heck cyclization of the major syn alcohol 37 provided the tricyclic structure 38 in $72 \%$ yield. The latter was then transformed to the ketone 27 in $7 \%$ yield over seven steps. Intermediate 27 was previously employed in Kozikowski's synthesis of huperzine (vide supra).

Koshiba et al developed a distinct synthesis of (-)-huperzine A (Figure 10B). ${ }^{83}$ Desymmetrization of the commercially available anhydride 39 , followed by six subsequent steps provided the key bicyclic intermediate 40 in $49 \%$ overall yield and $>99 \%$ ee. Treatment of 40 with trifluoromethanesulfonic acid initiated cation-olefin cyclization to form the tricyclic product 41 in $61 \%$ yield. The tricyclic product 41 was then converted to (-)-huperzine A (1) in 15 steps and $6 \%$ overall yield.

Tun et al reported an eight-step synthesis of (-)-huperzine A (1, Figure 11). The synthesis begins with the enantiomerically pure enone $42 .{ }^{84}$ The addition of phenyldimethylsilyl cuprate and trapping of the incipient enolate with the dibromopyridine 43 provided the addition-alkylation product 44 as a single diastereomer in $84 \%-91 \%$ yield. Cyanation, palladium-catalyzed enolate heteroarylation, and Wittig olefination then formed the exocyclic alkene 47 in $71 \%-76 \%$ yield over three steps (5:1 mixture of $\mathrm{E}$ and $\mathrm{Z}$ isomers). Four chemical modifications then provided (-)-huperzine A (1) in $56 \%-70 \%$ yield.

\section{Conclusion}

The manifold pharmacological effects of (-)-huperzine A (1), especially when considered in the context of its favorable toxicity profile, argue for its development for the treatment of neurological disorders. Although further study is required to fully elucidate the precise mechanisms underlying these effects, available evidence suggests (-)-huperzine A (1) is superior to many existing antineurodegenerative agents and may operate, in some instances, by orthogonal mechanisms. A long-standing impediment to the clinical development of (-)-huperzine A (1), especially in the United States, has been the lack of a stable and economical source of the metabolite. Recent advances in the total synthesis of (-)-huperzine A (1) may provide a solution to this latter problem.

\section{Disclosure}

The authors report no conflicts of interest in this work.

\section{References}

1. Baladrin MF, Kinghorn AD, editors. Human Medicinal Agents from Plants: ACS Symposium Series 534. Washington, DC: American Chemical Society; 1993.

2. Liu JS, Zhu YL, Yu CM, et al. The structures of huperzine A and B, two new alkaloids exhibiting marked anticholinesterase activity. Can J Chem. 1986;64(4):837-839.

3. Cheng DH, Ren H, Tang XC. Huperzine A, a novel promising acetylcholinesterase inhibitor. Neuroreport. 1996;8(1):97-101.

4. Wang H, Tang XC. Anticholinesterase effects of huperzine A, E2020, and tacrine in rats. Zhongguo Yao Li Xue Bao. 1998;19(1):27-30.

5. Wang YE, Yue DX, Tang XC. Anti-cholinesterase activity of huperzine A. Zhongguo Yao Li Xue Bao. 1986;7(2):110-113. 
6. Tang XC, Kindel GH, Kozikowski AP, Hanin I. Comparison of the effects of natural and synthetic huperzine-A on rat brain cholinergic function in vitro and in vivo. J Ethnopharmacol. 1994;44(3):147-155.

7. Raves ML, Harel M, Pang YP, Silman I, Kozikowski AP, Sussman JL. Structure of acetylcholinesterase complexed with the nootropic alkaloid, (-)-huperzine A. Nat Struct Biol. 1997;4(1):57-63.

8. Kozikowski AP, Tuckmantel W. Chemistry, pharmacology, and clinical efficacy of the Chinese nootropic agent huperzine A. Acc Chem Res. 1999;32(8):641-650.

9. Francis PT, Palmer AM, Snape M, Wilcock GK. The cholinergic hypothesis of Alzheimer's disease: a review of progress. J Neurol Neurosurg Psychiatry. 1999;66(2):137-147.

10. Ma X, Tan C, Zhu D, Gang DR. A survey of potential huperzine A natural resources in China: the Huperziaceae. J Ethnopharmacol. 2006;104(1-2):54-67.

11. Coupland R, Kobi-Renée L. Science and prohibited weapons. Science. 2005;308(5730):1841

12. Gordon JJ, Leadbeater L, Maidment MP. The protection of animals against organophosphate poisoning by pretreatment with a carbamate. Toxicol Appl Pharmacol. 1978;43(1):207-216.

13. Philippens IH, Wolthuis OL, Busker RW, Langenberg JP, Melchers BPC. Side effects of physostigmine as a pretreatment in guinea pigs. Pharmacol Biochem Behav. 1996;55(1):99-105.

14. Thal LJ, Schwartz G, Sano M, et al. A multicenter double-blind study of controlled-release physostigmine for the treatment of symptoms secondary to Alzheimer's disease. Neurology. 1996;47(6):1389-1395.

15. Grunwald J, Raveh L, Doctor BP, Ashani Y. Huperzine A as a pretreatment candidate drug against nerve agent toxicity. Life Sci. 1994;54(14):991-997.

16. Lallement G, Veyret J, Masqueliez C, Aubriot S, Burckhart MF, Baubichon D. Efficacy of huperzine in preventing soman-induced seizures, neuropathological changes and lethality. Fundam Clin Pharmacol. 1997;11(5):387-394.

17. Tonduli LS, Testylier G, Masqueliez C, Lallement G, Monmaur P. Effects of Huperzine used as pre-treatment against soman-induced seizures. Neurotoxicology. 2001;22(1):29-37.

18. Lallement G, Baille V, Baubichon D, et al. Review of the value of huperzine as pretreatment of organophosphate poisoning. Neurotoxicology. 2002;23(1):1-5.

19. Pibiri F, Kozikowski AP, Pinna G, et al. The combination of huperzine A and imidazenil is an effective strategy to prevent diisopropyl fluorophosphate toxicity in mice. Proc Natl Acad Sci U S A. September 16, 2008;105(37):14169-14174.

20. Dayan AD. Quantitative histological studies on the aged human brain II. Senile plaques and neurofibrillary tangles in senile dementia (with an appendix on their occurrence in cases of carcinoma). Acta Neuropathol. 1970;16(2):95-102.

21. Kang J, Lemaire HG, Unterbeck A, et al. The precursor of Alzheimer's disease amyloid A4 resembles a cell-surface receptor. Nature. 1987; 325(6106):733-736.

22. Lammich S, Kojro E, Postina R, et al. Constitutive and regulated alpha-secretase cleavage of Alzheimer's amyloid precursor protein by a disintegrin metalloprotease. Proc Natl Acad Sci U S A. 1999;96(7): 3922-3927.

23. Wallace WC, Akar CA, Lyons WE. Amyloid precursor protein potentiates the neurotrophic activity of NGF. Brain Res Mol Brain Res. 1997;52(2):201-212.

24. Mattson MP. Cellular actions of beta-amyloid precursor protein and its soluble and fibrillogenic derivatives. Physiol Rev. 1997;77(4): 1081-1132.

25. Loo DT, Copani A, Pike CJ, Whittemore ER, Walencewicz AJ, Cotman CW. Apoptosis is induced by beta-amyloid in cultured central nervous system neurons. Proc Natl Acad Sci U S A. 1993;90(17): 7951-7955.

26. Kasa P, Rakonczay Z, Gulya K. The cholinergic system in Alzheimer's disease. Prog Neurobiol. 1997;52(6):511-535.
27. Inestrosa $\mathrm{NC}, \mathrm{Alvarez} \mathrm{A}$, Calderon $\mathrm{F}$. Acetylcholinesterase is a senile plaque component that promotes assembly of amyloid beta-peptide into Alzheimer's filaments. Mol Psychiatry. 1996;1(5):359-361.

28. Alvarez A, Alarcon R, Opazo C, et al. Stable complexes involving acetylcholinesterase and amyloid-beta peptide change the biochemical properties of the enzyme and increase the neurotoxicity of Alzheimer's fibrils. J Neurosci. 1998;18(9):3213-3223.

29. Wang R, Zhang HY, Tang XC. Huperzine A attenuates cognitive dysfunction and neuronal degeneration caused by $\beta$-amyloid protein-(1-40) in rat. Eur J Pharmacol. 2001;421(3):149-156.

30. Peng Y, Jiang L, Lee DY, Schachter SC, Ma Z, Lemere CA. Effects of huperzine $\mathrm{A}$ on amyloid precursor protein processing and beta-amyloid generation in human embryonic kidney 293 APP Swedish mutant cells. J Neurosci Res. 2006;84(4):903-911.

31. Peng Y, Lee DY, Jiang L, Ma Z, Schachter SC, Lemere CA. Huperzine A regulates amyloid precursor protein processing via protein kinase $\mathrm{C}$ and mitogen-activated protein kinase pathways in neuroblastoma SK-N-SH cells over-expressing wild type human amyloid precursor protein 695 . Neuroscience. 2007;150(2):386-395.

32. Zhang HY, Liang YQ, Tang XC, He XC, Bai DL. Stereoselectivities of enantiomers of huperzine $A$ in protection against $\beta$-amyloid(25-35)induced injury in PC12 and NG108-15 cells and cholinesterase inhibition in mice. Neurosci Lett. 2002;317(3):143-146.

33. Contractor A, Heinemann SF. Glutamate receptor trafficking in synaptic plasticity. Sci STKE. 2002;156:re14.

34. Meldrum BS. Excitatory amino acids in epilepsy and potential novel therapies. Epilepsy Res. 1992;12(2):189-196.

35. Albin RL, Greenamyre JT. Alternative excitotoxic hypotheses. Neurology. 1992;42(4):733-738.

36. Ghasemi M, Schachter SC. The NMDA receptor complex as a therapeutic target in epilepsy: a review. Epilepsy Behav. 2011;22(4):617-640.

37. Manev H, Favaron M, Guidotti A, Costa E. Delayed increase of Ca2+ influx elicited by glutamate: role in neuronal death. Mol Pharmacol. 1989;36(1):106-112.

38. Beal MF. Mechanisms of excitotoxicity in neurologic diseases. FASEB J. 1992;6(15):3338-3344.

39. Ved HS, Koenig ML, Dave JR, Doctor BP. Huperzine A, a potential therapeutic agent for dementia, reduces neuronal cell death caused by glutamate. Neuroreport. 1997;8(4):963-967.

40. Gordon RK, Nigam SV, Weitz JA, Dave JR, Doctor BP, Ved HS. The NMDA receptor ion channel: a site for binding of Huperzine A. J Appl Toxicol. 2001;21(Suppl 1):S47-S51.

41. Zhang YH, Chen XQ, Yang HH, Jin GY, Bai DL, Hu GY. Similar potency of the enantiomers of huperzine A in inhibition of [(3)H] dizocilpine (MK-801) binding in rat cerebral cortex. Neurosci Lett. 2000;295(3):116-118

42. Coleman BR, Ratcliffe RH, Oguntayo SA, et al. [+]-Huperzine A treatment protects against N-methyl-D-aspartate-induced seizure/ status epilepticus in rats. Chem Biol Interact. 2008;175(1-3): 387-395.

43. Coyle JT, Puttfarcken P. Oxidative stress, glutamate, and neurodegenerative disorders. Science. 1993;262(5134):689-695.

44. Markesbery WR. Oxidative stress hypothesis in Alzheimer's disease. Free Radical Biol Med. 1997;23(1):134-147.

45. Ehmann WD, Markesbery WR, Alauddin M, Hossain TI, Brubaker EH. Brain trace elements in Alzheimer's disease. Neurotoxicology. 1986;7(1):195-206.

46. Good PF, Perl DP, Bierer LM, Schmeidler J. Selective accumulation of aluminum and iron in the neurofibrillary tangles of Alzheimer's disease: a laser microprobe (LAMMA) study. Ann Neurol. 1992;31(3): 286-292.

47. Samudralwar DL, Diprete CC, Ni BF, Ehmann WD, Markesbery WR. Elemental imbalances in the olfactory pathway in Alzheimer's disease. J Neurol Sci. 1995;130(2):139-145.

48. Smith CD, Carney JM, Starke-Reed PE, et al. Excess brain protein oxidation and enzyme dysfunction in normal aging and in Alzheimer disease. Proc Natl Acad Sci U S A. 1991;88(23):10540-10543. 
49. Hensley K, Hall N, Subramaniam R, et al. Brain regional correspondence between Alzheimer's disease histopathology and biomarkers of protein oxidation. J Neurochem. 1995;65(5):2146-2156.

50. Mecocci P, MacGarvey U, Kaufman AE, et al. Oxidative damage to mitochondrial DNA shows marked age-dependent increases in human brain. Ann Neurol. 1993;34(4):609-616.

51. Mecocci P, MacGarvey U, Beal MF. Oxidative damage to mitochondrial DNA is increased in Alzheimer's disease. Ann Neurol. 1994;36(5):747-751.

52. Lovell MA, Ehmann WD, Butler SM, Markesbery WR. Elevated thiobarbituric acid-reactive substances and antioxidant enzyme activity in the brain in Alzheimer's disease. Neurology. 1995;45(8):1594-1601.

53. Subbarao KV, Richardson JS, Ang LC. Autopsy samples of Alzheimer's cortex show increased peroxidation in vitro. JNeurochem. 1990;55(1):342-345.

54. Shang YZ, Ye JW, Tang XC. Improving effects of huperzine A on abnormal lipid peroxidation and superoxide dismutase in aged rats. Zhongguo Yao Li Xue Bao. 1999;20(9):824-828.

55. Behl C, Davis JB, Lesley R, Schubert D. Hydrogen peroxide mediates amyloid $\beta$ protein toxicity. Cell. 1994;77(6):817-827.

56. Whittemore ER, Loo DT, Watt JA, Cotmans CW. A detailed analysis of hydrogen peroxide-induced cell death in primary neuronal culture. Neuroscience. 1995;67(4):921-932.

57. Xiao XQ, Yang JW, Tang XC. Huperzine A protects rat pheochromocytoma cells against hydrogen peroxide-induced injury. Neurosci Lett. 1999;275(2):73-76.

58. Tang XC. Huperzine A (shuangyiping): a promising drug for Alzheimer's disease. Zhongguo Yao Li Xue Bao. 1996;17(6):481-484.

59. Lu WH, Shou J, Tang XC. Improving effect of huperzine A on discrimination performance in aged rats and adult rats with experimental cognitive impairment. Zhongguo Yao Li Xue Bao. 1988;9(1):11-15. Chinese.

60. Ye JW, Cai JX, Wang LM, Tang XC. Improving effects of huperzine A on spatial working memory in aged monkeys and young adult monkeys with experimental cognitive impairment. J Pharmacol Exp Ther. 1999;288(2):814-819.

61. Xu SS, Gao ZX, Weng Z, et al. Efficacy of tablet huperzine-A on memory, cognition, and behavior in Alzheimer's disease. Zhongguo Yao Li Xue Bao. 1995;16(5):391-395.

62. Xu SS, Cai ZY, Qu ZW, et al. Huperzine-A in capsules and tablets for treating patients with Alzhiemer disease. Zhongguo Yao Li Xue Bao. 1999;20(6):486-490.

63. Zhang Z, Wang X, Chen Q, Shu L, Wang J, Shan G. Clinical efficacy and safety of huperzine Alpha in treatment of mild to moderate Alzheimer disease, a placebo-controlled, double-blind, randomized trial. Zhonghua Yi Xue Za Zhi. 2002;82(14):941-944.

64. Sun QQ, Xu SS, Pan JL, Guo HM, Cao WQ. Huperzine-A capsules enhance memory and learning performance in 34 pairs of matched adolescent students. Zhongguo Yao Li Xue Bao. 1999;20(7):601-603.

65. Rafii MS, Walsh S, Little JT, et al; for Alzheimer's Disease Cooperative Study. A phase II trial of huperzine A in mild to moderate Alzheimer disease. Neurology. 2011;76(16):1389-1394.

66. Bai DL, Tang XC, He XC. Huperzine A, a potential therapeutic agent for treatment of Alzheimer's disease. Curr Med Chem. 2000;7(3):355-374.
67. Xia Y, Kozikowski AP. A practical synthesis of the Chinese "nootropic" agent huperzine A: a possible lead in the treatment of Alzheimer's disease. J Am Chem Soc. 1989;111(11):4116-4117.

68. Qian L, Ji R. A total synthesis of (+/-)-huperzine A. Tetrahedron Lett. 1989;30(16):2089-2090.

69. Kozikowski AP, Reddy ER, Miller CP. A simplified route to a key intermediate in the synthesis of the Chinese nootropic agent huperzine A. J Chem Soc Perkin 1. 1990;1:195-197.

70. Chassaing C, Haudrechy A, Langlois Y. New straightforward route to a huperzine A synthetic intermediate. Synthetic Communocatopms. 1997;27(1):61-68.

71. Haudrechy A, Chassaing C, Riche C, Langlois Y. A formal synthesis of (+)-huperzine A. Tetrahedron. 2000;56(20):3181-3187.

72. Yamada F, Kozikowski AP, Reddy ER, Pang YP, Miller JH, McKinney M. A route to optically pure (-)-huperzine A; molecular modeling and in vitro pharmacology. J Am Chem Soc. 1991;113(12):4695-4696.

73. Kaneko S, Yoshino RT, Katoh T, Terashima S. An enantioselective synthesis of (-)-huperzine A via Cinchona alkaloids-promoted asymmetric Michael reaction. Heterocycles. 1997;46(1):27-30.

74. Kaneko S, Yoshino T, Katoh T, Terashima S. Synthetic studies of huperzine A and its fluorinated analogues. 1. Novel asymmetric syntheses of an enantiomeric pair of huperzine A. Tetrahedron. 1998;54(21):5471-5484.

75. Campiani G, Sun LQ, Kozikowski AP, Aagaard P, McKinney M A palladium-catalyzed route to huperzine A and its analogs and their anticholinesterase activity. J Org Chem. 1993;58(27):7660-7669.

76. Kaneko S, Yoshino T, Katoh T, Terashima S. A novel enantioselective synthesis of the key intermediate of (-)-huperzine a employing asymmetric palladium-catalyzed bicycloannulation. Tetrahedron Asymmetry. 1997;8(6):829-832.

77. He XC, Wang B, Yu G, Bai D. Studies on the asymmetric synthesis of huperzine A. Part 2: Highly enantioselective palladium-catalyzed bicycloannulation of the $\beta$-keto-ester using new chiral ferrocenylphosphine ligands. Tetrahedron Asymmetry. 2001;12(23):3213-3216.

78. Lee IYC, Jung MH, Lee HW, Yang JY. Synthesis of huperzine intermediates via $\mathrm{Mn}(\mathrm{III})$-mediated radical cyclization. Tetrahedron Lett. 2002;43(13):2407-2409.

79. Ward J, Caprio V. A radical mediated approach to the core structure of huperzine A. Tetrahedron Lett. 2006;47(4):553-556.

80. Ward J, Caprio V. Synthesis of the bicyclo[3.3.1]nonane core of huperzine A and novel pyridine-fused tricycles by cyclisation of pyridinebased radicals. Heterocycles. 2009;79(1):791-804.

81. Ward J, Johnson AB, Clark GR, Caprio V. The synthesis of functionalised bicyclo[3.3.1]nonanes related to huperzine A. Synthesis. 2009:3411-3418.

82. Lucey C, Kelly SA, Mann J. A concise and convergent (formal) total synthesis of huperzine A. Org Biomol Chem. 2007;5(2):301-306.

83. Koshiba T, Yokoshima S, Fukuyama T. Total synthesis of(-)-huperzine A. Org Lett. 2009;11(22):5354-5356.

84. Tun MKM, Wustmann DJ, Herzon SB. A robust and scalable synthesis of the potent neuroprotective agent (-)-huperzine A. Chem Sci. 2011;2(11):2251-2253.
Journal of Experimental Pharmacology

\section{Publish your work in this journal}

The Journal of Experimental Pharmacology is an international, peerreviewed, open access journal publishing original research, reports, reviews and commentaries on all areas of laboratory and experimental pharmacology. The manuscript management system is completely online and includes a very quick and fair peer-review system.

\section{Dovepress}

Submit your manuscript here: http://www.dovepress.com/journal-of-experimental-pharmacology-journal 